\title{
GAIA Level 3 Low Birth Weight
}

National Cancer Institute

\section{Source}

National Cancer Institute. GAlA Level3 Low Birth Weight. NCI Thesaurus. Code C128727.

GAIA Level 3 Low Birth Weight is defined by three criteria: first, a newborn infant must be weighed within the first 48 hours of life; second, weight is measured using a dial/ spring/ color-coded scale; third, weight is assessed as less than 2500 grams. 